\title{
MOVER-SE OU NÃO MOVER-SE? AS MÚLTIPLAS PANDEMIAS A PARTIR DE TRÂNSITOS E NARRATIVAS DE UMA SOLICITANTE DE REFÚGIO LÉSBICA AO SUL GLOBAL
}

\author{
To Move or not to Move? Multiple Pandemics from Transits and \\ Narratives of a Lesbian Asylum Seeker in the Global South
}

Resumo. A questão da mobilidade tem ganhado destaque durante a pandemia de Covid-19, onde políticas de restrição vêm sendo implementadas como um dos dispositivos de controle epidemiológico mais comuns ao redor do mundo. Este artigo busca analisar algumas tensões, discursos e silêncios em torno dos fluxos de retorno ("voluntário"?) de migrantes e refugiados venezuelanos na Colômbia e no Brasil no contexto pandêmico. Em seguida, busca evidenciar como marcadores sociais de diferença modulam impactos desiguais da pandemia, sobretudo nas (re)configurações das mobilidades, tomando como foco a narrativa de uma mulher lésbica venezuelana e solicitante de refúgio no Brasil. Pretendendo apresentar e "contar" (no sentido de narrar) a pandemia como um evento biográfico, defendendo ser esta uma das principais contribuições das ciências sociais para a compreensão deste contexto.

Palavras-chave: mobilidade; COVID-19; refúgio; LGBTI; narrativas.

\begin{abstract}
The issue of mobility has gained prominence during the Covid-19 pandemic, where restriction policies have been implemented as one of the most common epidemiological control devices around the world. This article seeks to analyze some tensions, discourses, and silences surrounding the return flows ("voluntary"?) of Venezuelan migrants and refugees in Colombia and Brazil in the pandemic context. Then, it seeks to show how social markers of difference modulate the unequal impacts of the pandemic, especially in the (re) configurations of mobilities, focusing on the narrative of a Venezuelan lesbian and asylum seeker in Brazil. Intending to present and "tell" (in the sense of narrating) the pandemic as a biographical event, arguing that this is one of the main contributions of the social sciences to the understanding of this context.
\end{abstract}

Keywords: mobility; COVID-19; refuge; LGBTI; narratives.

Doutoranda em Saúde Coletiva na área de Ciências Humanas e Saúde pelo Instituto de Medicina Social Hesio Cordeiro da Universidade do Estado do Rio de Janeiro (IMS/UERJ). Rio de Janeiro, RJ, Brasil. E-mail: nathaliaaf20@gmail.com. Orcid: https://orcid.org/0000-0002-5733-5202. 


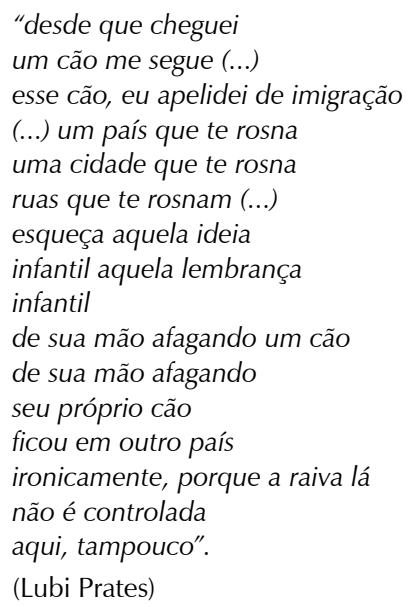

\section{Introdução}

A pandemia do Covid-19 segue alterando nosso cotidiano. Nesse período, a mobilidade tem sido considerada um marcador de risco e disseminação do vírus, definidora de pureza e perigo (Douglas, 1966). Somos os veículos carreadores do mesmo para todas as partes do mundo. Dessa maneira, políticas de restrição de mobilidades, em diversos graus e níveis, vêm sendo implementadas como um dos dispositivos de controle epidemiológico mais comuns ao redor do mundo.

Em recente comentário, Sérgio Carrara (2020) problematiza o reducionismo acoplado nas representações visuais que tentam reproduzir os diferentes cenários da pandemia em relação à realização do "isolamento social" ou não. Nas imagens, conjuntos de pontinhos iguais se movimentam mais ou menos rápido determinando a disseminação mais ou menos acelerada do vírus. Carrara, sem negar tais modelos, discute como a aproximação gráfica de "pessoas-pontinhos" idênticos acaba por ocultar as muitas diferenças sociais implicadas, deixando de lado a singularidade dos indivíduos e a relevância dos marcadores sociais, tais como raça, gênero, classe, sexualidade etc. Em adição, o autor também critica a "ideia de que indivíduos se movimentam em uma espécie de branca planície, uma superfície plana, lisa e homogênea, contida apenas pelas bordas do quadro (...) Seriam as fronteiras de um país?" (2020, p. 3), o que nos leva a refletir que por trás dos pontinhos iguais estão condições desiguais de vida e mobilidade, sobre as quais esse artigo discutirá. As primeiras pessoas a serem confirmadas com a doença em diferentes países do mundo tinham em seus históricos recentes viagens internacionais por locais que marcavam os epicentros da doença, sobretudo o território Europeu, considerado pela análise do veículo The Intercept como "pólo de contágio global"1. Quanto mais as pessoas se movimentam, mais o vírus segue colonizando.

\footnotetext{
1 Disponível em: < https://theintercept.com/2020/04/04/coronavirus-europa-china/> .
} 
Os vírus, agentes infecciosos, submicroscópicos, que há quase duzentos anos são estudados pelas ciências médicas e biológicas estão hoje, aparentemente, no centro de uma grande crise social mundial. Enquanto a mobilidade humana, direito universal, marca do liberalismo e dos regimes democráticos e objeto de estudo de diversos campos das ciências sociais e antropológicas, está, nessa pandemia, cada vez mais sob o olhar do biopoder biomédico. Entretanto, como aponta Svetlana Ruseishvili (2020), a "mobilidade deve ser pensada em relação à imobilidade". Ao analisar algumas lições da pandemia sobre mobilidade no mundo contemporâneo, a autora chama atenção para a determinação dos privilégios a partir do binômio mobilidade/imobilidade. Os países tentam reforçar as linhas imaginárias segmentadoras na expectativa de isolar a exterioridade ameaçadora e as pessoas, aquelas que podem (do verbo poder), imobilizam-se como uma forma de "imunidade" que se equilibra sobre as frágeis desigualdades persistentes. Paul Preciado (2020) nos atenta que esta estratégia não é um sintoma da pandemia, mas antes: é implementada há anos pelas políticas restritivas anti-migratórias sustentadas principalmente por países europeus. Em sua reflexão Preciado parece resumir bem a oposição dessas duas políticas: “La destrucción de Europa comenzó paradójicamente con esta construcción de una comunidad europea inmune, abierta en su interior y totalmente cerrada a los extranjeros y migrantes".

Portanto, não é de hoje - e, certamente não é dessa pandemia - que as relações de poder envolvidas nas dinâmicas de mobilidade/imobilidade humanas demarcam fronteiras sociais. Diferentes marcadores sociais, tais como classe, gênero, raça, nacionalidade, sexualidade, ao longo da história, determinaram uma espécie de "cordão sanitário social" entre seres humanos. Essas políticas de segregação e demarcação de fronteiras sociais se estendem até os dias atuais. Ortega e Behague (2020) discutem como as intervenções de "tamanho único", que pressupõem aplicabilidade global e homogênea, ocultam a expressão dos marcadores sociais em diferentes localidades e contextos sociais, funcionando como dispositivos de controle neocoloniais necrobiopolíticos. E com isso evidenciam mais uma forma (colonial) de mobilidade em cena: o trânsito dos protocolos de controle epidemiológico/biomédico de países do Norte para países do Sul. Os autores, ao discutir sobre as políticas de lockdown em contextos vulneráveis, provocam nos leitores a pergunta: "Lockdown, pra quem?".

Para migrantes e refugiados que, como citou Bruno Latour (2020): "por definição não podem ser isolados em nenhuma casa própria", a mobilidade é uma condição persistente. Lubi Prates (2019), cujo poema "Condição Imigrante" trago na epígrafe, retrata na figura do cão imigração essa sensação de nunca poder estar em "casa". Motivada pelo desejo de abrir diálogo sobre as múltiplas formas de "rosnado" vivenciadas por migrantes e refugiados durante a pandemia de Covid-19 busco dialogar neste artigo com a discussão mais ampla apresentada nesta introdução sobre como essa pandemia tem (re)configurado as dinâmicas 
das mobilidades humanas. Para isso, analiso algumas tensões, discursos e silêncios em torno dos fluxos de retorno ("voluntários"?) de migrantes e refugiados Venezuelanos na Colômbia e no Brasil durante a pandemia do Covid-19. Em seguida, buscando evidenciar como marcadores sociais da diferença modulam impactos desiguais da pandemia nas (re)configurações das mobilidades, tomo como foco a trajetória de uma mulher lésbica venezuelana e solicitante de refúgio no Brasil. A partir do encontro etnográfico com Alejandra (nome fictício) pretendo apresentar e "contar" (no sentido de narrar) a pandemia como um evento biográfico, defendendo ser esta uma das principais contribuições das ciências sociais para a compreensão deste contexto.

\section{Retornos "voluntários", pra quem?}

Ao dissertar sobre as contribuições da medicina social latino-americana no debate sobre a pandemia de Covid-19, Ortega e Behague (2020) argumentam sobre a possibilidade da implementação de políticas do tipo lockdown no Brasil. Em meio a essa discussão, os autores trazem o exemplo da Índia que, ao determinar o confinamento total repentino, ocasionou o maior fluxo populacional de retorno desde o evento da Partição. Muito mais próximo de nós, outro fluxo migratório tem chamado atenção durante a pandemia de Covid-19. No dia 29 de abril de 2020, a autoridade migratória colombiana publicou comunicado oficial intitulado: "No podemos permitir que la salida desordenada de venezolanos ponga en riesgo al país" ${ }^{\prime 2}$. O comunicado refere-se ao intenso fluxo populacional de venezuelanos em direção ao território da Venezuela após o início da pandemia de Covid-19 e da implementação das medidas de isolamento social. No texto, o governo colombiano utiliza a expressão "retornos voluntários" para se referir a esse movimento populacional ocasionado em grande parte pela grave crise socioeconômica provocada pela pandemia de Covid-19. E determina que todo cidadão venezuelano "que não cumpra as medidas de isolamento obrigatório será sujeito a medidas sancionatórias de tipo administrativo e penal" ${ }^{3}$, restringindo o movimento de retorno a apenas 300 pessoas por dia, três vezes na semana ${ }^{4}$.

Segundo informações do governo bolivariano, cerca de 115 mil migrantes e refugiados venezuelanos que estavam na Colômbia, retornaram para a Venezuela desde o início da pandemia ${ }^{5}$. Durante reunião virtual da Red de Movilidad Humana $L G B T I+{ }^{6}$, no dia 22 de abril de 2020, um representante da ONG Caribe

2 Disponível em: <https://www.migracioncolombia.gov.co/noticias/265-abril-2020/no-podemospermitir-que-la-salida-desordenada-de-venezolanos-ponga-en-riesgo-al-pais > .

3 Ibidem.

4 O número máximo e a frequência de entrada foram determinados pelo governo do Presidente Nícolas Maduro na Venezuela.

5 Ver: <https://www.elcomercio.com/actualidad/cierre-frontera-colombia-migracion-venezolanos.html>.

6 Em 2019 consolidou-se Red de Movilidad Humana LGBTI+ formada por organizações nãogovernamentais, como a LGBT+Movimento, que lidam no apoio direto a migrantes e refugiados, 
Afirmativo, que tem sede na cidade de Barranquilla, ao Norte colombiano, afirmou que o governo federal criou um programa de subsídios chamado Ingreso Solidario que prevê um auxílio de 320 mil pesos colombianos (cerca de 80 dólares) pagos em duas parcelas para os cidadãos. Comentou, porém, que migrantes e refugiados venezuelanos não têm acesso ao benefício, agravando inúmeras situações de vulnerabilidade.

Enquanto o ACNUR (Alto Comissariado das Nações Unidas para os Refugiados) utiliza o termo "deslocamento forçado" para se referir ao conjunto de solicitantes de refúgio, refugiados e deslocados internos no mundo, marcando os episódios de perseguição, violência e violações dos direitos humanos determinantes nestes contextos, o governo colombiano, em meio ao evento crítico (Das, 2015) da pandemia do Covid-19, disruptor da continuidade espaço-temporal mundial, faz referência ao fluxo de retorno de refugiados e migrantes venezuelanos como "retornos voluntários". Aponto duas hipóteses para a opção desse termo por parte do governo colombiano: uma delas se baseia no "princípio da não devolução" de refugiados, proteção que é estabelecida pela Convenção de 1951, relativa ao Estatuto dos Refugiado (UNHCR, 1951). O princípio proíbe a devolução de refugiados ao território "em que a sua vida ou a sua liberdade está ameaçada em virtude da sua raça, religião, nacionalidade, do grupo social a que pertence ou das suas opiniões políticas", como dispõe o artigo 33 desta convenção. Dessa maneira, poderíamos considerar a escolha pelo termo "retornos voluntários" por parte do governo colombiano como de cunho político-diplomático, a fim de não se responsabilizar institucionalmente por aqueles que decidem retornar - por isso a ênfase na caracterização "voluntária". Entretanto, com o estabelecimento das políticas de isolamento social na Colômbia pela pandemia, grande parte dos migrantes e refugiados venezuelanos, que são dedicados ao trabalho informal, estão sem fonte de renda. Sem também receber o auxílio em dinheiro do governo para sobrevivência, muitos se viram em situação de rua.

Nesta situação, onde está o caráter "voluntário", atribuído? Quando tanto a mobilidade (do retorno) quanto a imobilidade (do ficar) representam perigo, o que pode ser tomado como voluntário? Ethienne Luibhéid (2019) durante análise crítica das categorias de migrante e de refugiado argumenta que a primeira é comumente associada a processos voluntários, de agência, enquanto a segunda é geralmente ligada a processos forçados, imbuídos de sofrimento. Segundo a autora o binário voluntário/forçado apaga o fato de que:

que se identificam e são identificados como parte da referida população "LGBTI+" (Lésbicas, Gays, Bissexuais, Mulheres e Homens Transexuais, Travestis e Intersexo e outras identidades que não referidas no acrônimo, representadas pelo "+"), ver Aguião (2014). Fazem parte da Rede organizações do Brasil, Colombia, Chile, Peru, Equador, México, Argentina e Venezuela e espaço tem sido utilizado para articulação e exposição das problemáticas associadas ao acolhimento, proteção e integração dessas pessoas. 
a maioria dos migrantes/refugiados experimenta condições tanto forçadas quanto de livre-arbítrio e escolha, em diversos graus e variantes. Ainda mais importante que isso, é que este binário é utilizado pelos Estados para tentar imobilizar e criminalizar uma parcela específica de migrantes/refugiados, por meio de lógicas econômicas ou humanitárias. (Luibhéid, 2019, p. 8)

Além de tentar proteger-se das acusações de quebra do "princípio de não-devolução" de refugiados, o governo colombiano também procura manter sua imagem moral na intersecção do "político" e do "humanitário". Espaço definidor dos sentimentos morais que, segundo Didier Fassin (2012), compõem a força essencial da política contemporânea. A Colômbia é o país que mais recebeu migrantes e refugiados venezuelanos em diáspora - a cifra se aproxima a dois milhões de pessoas. A revisão do orçamento do RMRP (Plano de Resposta Regional para Migrantes e Refugiados da Venezuela) durante a pandemia, plano composto por países latino americanos e caribenhos, foi finalizada no dia 11 de maio de 2020 com requerimento financeiro total de 1.41 bilhões de dólares, dos quais 782,3 milhões de dólares correspondem às requisições colombianas. Apesar de apenas 3,3\% estarem atualmente sob financiamento (cerca de 25,5 milhões de dólares), o ACNUR e a OIM ( Organização Internacional de Migração), em parceria com a União Europeia e o Governo da Espanha, organizaram uma conferência internacional de doadores em solidariedade com refugiados e migrantes venezuelanos no marco da Covid-19, que aconteceu no dia 26 de maio de 2020. Nesse evento os doadores internacionais assinaram compromissos financeiros por um total de 2,7 bilhões de dólares, dos quais 692 milhões em doações ${ }^{7}$.

Exponho as cifras numéricas arrecadas não na intenção de problematizar ou negar a necessidade de recursos financeiros para atividades de escopo humanitário, mas de reconhecer o argumento de Fassin (2012) sobre o lugar de poder que o humanitarismo ocupa hoje no mundo. A utilização do termo "retornos voluntários" configura como estratégia de manutenção da relação do governo colombiano com as agências que lideram o governo humanitário milionário para migrantes e refugiados no país. Analisando o uso do termo pela ótica de Fassin (2012) sobre como os sentimentos morais nutrem discursos e legitimam práticas de governo humanitário, a categorização dos retornos como voluntários remete à discussão de Facundo (2014) sobre a produção contínua do refugiado como "anormal", ou melhor, como fora da ordem e do poder do Estado. Essa visão autoriza o tratamento dos refugiados como sujeitos que necessitam de intervenção "para serem restituídos a uma condição de normalidade, que possa restaurar sua existência social" (2014, p. 27), evidenciando as dinâmicas de governo na administração destes sujeitos. A partir da experiência de seus interlocutores, Facundo discute a diferença entre repatriação voluntária e regresso. A repatriação voluntária é mediada por agências supranacionais, como o ACNUR, e conta com assessoria, acompanhamento e financiamento para sua concretização, configurando-se como um processo lento e

Disponível em: < https://ec.europa.eu/commission/presscorner/detail/es/ip_20_922>. 
cuidadoso. O "simples regresso" como se refere Facundo, e que se aproxima a noção de "retornos voluntários", usado pelo governo colombiano implica, sobretudo nos casos de solicitação de refúgio, que o sujeito ao realizar o movimento de retorno "renúncia à proteção das agências, mediante a firma de documentos com os que a eximiria de responsabilidades" e, além disso, "significa também que as pessoas não contaram com apoio financeiro nem assistência nenhuma para a viagem (ou as viagens) de regresso e que perderam chances de voltarem a serem aceitos como refugiados no futuro" (Facundo, 2014, p. 345).

No Brasil, a portaria ${ }^{\circ} 125$ de 19 de março de 2020 restringiu a entrada de estrangeiros no país e autorizou o fechamento da fronteira com a Venezuela - e assim permanece até o momento. A complexidade envolvida na temática dos fluxos de retorno de migrantes, solicitantes de refúgio e refugiados venezuelanos impactados pela pandemia de Covid-19 tem sido marcada pelo pouco destaque do tema no cenário brasileiro. A R4V (Response for Venezuelans), plataforma regional de coordenação interagencial responsável pela direção e coordenação da resposta a migrantes e refugiados venezuelanos na América Latina e Caribe, informou pela primeira vez publicamente em um flash update, no dia 13 de maio de $2020^{8}$, que desde o fechamento da fronteira cerca de 792 venezuelanos haviam retornado oficialmente à Venezuela pela via terrestre, no município de Pacaraima. No mesmo informe, a R4V chama atenção para a subdimensão da cifra pois até o final do mês de abril os retornos não estavam sendo registrados sistematicamente, de maneira que o número não representa o total de retornos desde o fechamento da fronteira. Ao final do informe, revelam que segundo entrevistas feitas por agências parceiras da R4V a maioria dos venezuelanos em situação de retorno relatou que a causa da partida é a perda dos meios de vida e subsistência e a incapacidade de pagar aluguel.

Em agosto de 2020, a mesma plataforma lançou um relatório de "monitoramento do retorno de refugiados e migrantes venezuelanos", onde, segundo dados da polícia federal, cerca de 2.304 venezuelanos retornaram à Venezuelana entre o período de março a julho de 2020. Dessa vez, ao invés da motivação de saída ser atribuída a causas econômicas, as entrevistas apontaram que $62,6 \%$ das pessoas retornaram ao seu país de origem devido a causas familiares, como por exemplo doença e morte de parentes. Além disso, 60,7\% dos entrevistados ressaltaram como fator incentivador do retorno a presença de redes de apoio na Venezuela e cerca de $79 \%$ disse ter intenção de voltar ao Brasil novamente.

Os veículos midiáticos brasileiros pouco abordaram a temática dos retornos durante o contexto da pandemia de Covid-19. A mobilidade transnacional que pareceu ser mais reconhecida por esses veículos diz respeito aos retornos de cidadãos aos seus próprios países por meio de voos humanitários, sem mencionar

${ }_{8}$ Disponível em: < https://data2.unhcr.org/es/documents/download/76433>. 
a situação de muitos que não podem retornar aos seus países ainda que desejem e, mais importante que isso, sem ressaltar o papel das desigualdades como dimensão central nas dinâmicas de mobilidade/imobilidade durante a pandemia de Covid-19. Em relação aos migrantes e refugiados no território brasileiro, as dinâmicas de mobilidade são em muitos casos distintas daquelas vivenciadas em países menos extensos como a Colômbia, por exemplo, não permitindo o acesso fácil ou economicamente viável às regiões fronteiriças com a Venezuela. No caso de migrantes e refugiados venezuelanos muitos conseguiram se deslocar dos estados da região Norte, próximos à fronteira, para as regiões Sudeste e Sul através da participação no programa de interiorização coordenado pela Operação Acolhida, que em parceria com agências humanitárias e da sociedade civil já realizou a interiorização de 45.233 venezuelanos para diversas cidades brasileiras, até dezembro de $2020^{9}$.

O agravamento das condições socioeconômicas devido à pandemia de Covid-19, as dificuldades burocráticas e práticas do deslocamento de retorno e o fechamento das fronteiras, têm (re)configurado as mobilidades de migrantes e refugiados durante o contexto pandêmico. Nas sessões seguintes busco explorar impactos da pandemia nas trajetórias de uma mulher lésbica venezuelana e solicitante de refúgio.

\section{A terceira dimensão do "contar"}

Lucas Freire (2020) nos apresenta, em recente comentário, reflexões sobre como a subnotificação de casos de Covid-19 participa da construção daquilo que tomamos como realidade. Estando, portanto, diretamente ligados a episódios de negacionismo em relação à gravidade da pandemia no Brasil e no mundo. Nesse comentário, Freire sugere que cabe a nós, cientistas sociais, indagar acerca do que "conta" como real, no duplo sentido do verbo contar, isto é, no sentido de "calcular e contabilizar" e no sentido de "fazer importar, valer, ter em consideração". Chamo atenção para um terceiro sentido do verbo: o de narrar, contar histórias e experiências. Este sentido soma-se aos outros dois na importante reflexão sobre o estabelecimento daquilo que conta como real e daquilo que é descartado em meio a pandemia de Covid-19. Como ressalta Richard Horton (2020), a pandemia não deve ser compreendida apenas como um evento biológico, mas também como um evento biográfico, de forma que as Ciências Sociais têm papel fundamental na contribuição dessa terceira dimensão do "contar". É preciso reconhecer como as formas de governo e desgoverno durante a pandemia de Covid-19 "descem ao cotidiano" (Das, 2020), afetando as pessoas, e de que formas elas têm gerido suas mobilidades e imobilidades nesse contexto.

\footnotetext{
${ }_{9}$ Cf. <http://blog.mds.gov.br/redesuas/painel-de-dados-da-interiorizacao-de-migrantes-e-refugiadosvenezuelanos/>.
} 
Venho acompanhando, desde 2018, enquanto coordenadora da organização LGBT+Movimento, a trajetória de vida de algumas pessoas migrantes e refugiadas. A LGBT+Movimento é uma organização que, desde 2017, realiza o atendimento direto a pessoas migrantes e refugiadas que se identificam enquanto sujeitos "LGBTI+" e tem como uma de suas propostas a articulação de redes de afeto, proteção e integração para estas na cidade do Rio de Janeiro. O lugar de coordenadora e a relação de intimidade duradoura estabelecida com algumas interlocutoras me permitiram entender, de maneira privilegiada, especificidades da migração venezuelana, durante minha pesquisa de mestrado, com experiências de vida de mulheres trans e lésbicas venezuelanas e solicitantes de refúgio que haviam se deslocado para Boa Vista e foram, posteriormente, interiorizadas para a cidade do Rio de Janeiro. Durante a pandemia de Covid-19 continuei acompanhando a trajetória de vida de algumas interlocutoras, dentre elas a de Alejandra. É importante ressaltar que não uso a trajetória de Alejandra como uma suposta exemplaridade de "refúgio LGBTI+"10 em tempos de pandemia, pelo contrário, o trabalho na LGBT+Movimento e as relações de intimidade estabelecidas me permitiram acompanhar de maneira privilegiada como a pandemia tem atravessado trajetórias de mobilidade nas margens (Das, Poole, 2004), bem como compreender como se (re)configuram essas mobilidades em tempos de pandemia a partir de uma trajetória singular configurada pela articulação entre gênero, sexualidade, nacionalidade e estatuto migratório.

Conheci Alejandra no dia 23 de janeiro de 2019 por intermédio de uma agente de proteção do ACNUR. Ela havia chegado em uma casa de acolhida para mulheres solicitantes de refúgio interiorizadas aqui no Rio no dia 31 de dezembro de 2018. Das 29 mulheres da casa, Alejandra era a única mulher lésbica. Em poucos minutos de conversa compreendi sua maior angústia: não ter meios de comunicação para conseguir falar com nenhuma das três filhas (13, 11 e 6 anos de idade) há mais de três meses. As filhas haviam ficado na Venezuela com os avós paternos e o pai, após sua migração para o Brasil por motivos relacionados à crise sócio-econômica generalizada no país, somados à perseguição e ameaça pela sua orientação sexual, principalmente por parte de seu pai e do ex-marido.

Alejandra saiu da casa dos pais com 16 anos pois não tinha boa relação com o pai e os irmãos, mas para sair de casa precisava de outra para se mudar. Decidiu então casar-se com um homem - apesar de afirmar que já se compreendia enquanto uma mulher lésbica, esta lhe pareceu a única forma de não ficar em situação de rua e manter as visitas a mãe, que tinha saúde debilitada, mas que era

${ }_{10}$ Utilizo o termo entre aspas pois assim como França e Fontgaland (2020) compreendo as categorias de refugiado e LGBTI como construções histórias e situadas. No que concerne ao "refúgio LGBTI" desde 2002 agências transnacionais das Nações Unidas têm reconhecido que o pertencimento a "grupo social" específico como justificativa para solicitação de refúgio a pessoas que sofreram fundado temor de perseguição por motivos ligados a sua orientação sexual ou identidade de gênero ou que se qualificam como vítimas potenciais para tal. 
a única que sabia e aceitava sua orientação sexual. Teve as três filhas e a situação do casamento foi piorando cada vez mais com episódios de violência doméstica. Ela tentou prestar queixas, mas não eram registradas. Segundo ela, a devolutiva dos serviços públicos de proteção à mulher na Venezuela dizia que "em briga de marido e mulher não se mete colher". Aos 26 anos decidiu assumir-se como lésbica e deixar o marido. A partir daí os episódios de violência por parte do marido pioraram ainda mais. Ele a acusou de maltratar as filhas e postou nas redes sociais que ela era lésbica e que convivia com HIV/AIDS (o que não é verdade), episódios que, segundo ela, tornaram a sua permanência no trabalho como policial insustentável - mesmo ela portando a todo momento o exame negativo e afirmando que sua orientação sexual não interferia no trabalho.

Passou então a viver em situação de rua na cidade de Anzoátegui, com eventual ajuda de outros parentes. Só conseguia ver as filhas na saída do colégio. Seu último ano na Venezuela, antes de vir para o Brasil, foi profundamente marcado pelo desenvolvimento do câncer da mãe. Proibida de vê-la pelo pai, que a culpava pela doença, e já com a Venezuela em situação político-econômica complexa, Alejandra deslocou-se internamente na Venezuela duas vezes antes de vir ao Brasil. Veio após a ocasião da morte da mãe e episódios de violência do pai durante os rituais funerários. Durante os dois dias de carona que pegou para chegar a Santa Helena (cidade fronteiriça com Brasil), contou que sofreu duas tentativas de estupro, por estar sozinha e ser mulher. Nessa cidade permaneceu por alguns dias e, antes de atravessar para o Brasil, encontrou uma ex-namorada. Mas ao trocar carinhos com ela na rua, foi golpeada por dois homens venezuelanos. Fugiu, então, em direção à fronteira com Pacaraima e pediu refúgio no Brasil em outubro de 2018. Ficou três dias em Pacaraima para conseguir a documentação e depois seguiu para Boa Vista a pé. Dormiu na praça Simon Bolívar por algumas semanas e depois conseguiu entrar no abrigo Latife Salomão, onde são encaminhados grande parte da referida "população LGBTI+" (Aguião, 2014) de venezuelanos.

Alejandra foi interiorizada para o Rio de Janeiro e ficou abrigada em uma casa de acolhida para mulheres migrantes e refugiadas, localizada na zona oeste da cidade, onde relatou sofrer preconceito por parte das outras moradoras da casa que, segundo ela, afirmavam se sentir incomodadas com sua sexualidade e expressão de gênero associadas por elas a masculinidade. Situação que a fez deixar a casa de acolhida antes dos três meses previstos, mudando-se para casa de amigos venezuelanos na comunidade da Gardênia Azul, também na zona oeste da cidade. De fevereiro a dezembro de 2019, Alejandra participou de quase vinte entrevistas de emprego e entregou muitos currículos pela cidade, mas nunca conseguiu ser efetivada em um emprego formal. Vivia de pequenos bicos e mudou-se seis vezes nesse período, sempre para casa de amigos, nunca para sua própria. Em dezembro, decidiu tentar a vida em Dourados, município de Mato-Grosso do Sul, onde seu irmão mora com a família e trabalha em um dos frigoríficos da empresa JBS - ela 
disse que a ideia de revê-lo a reconfortou pois precisava do "calor da família" e acreditou que o irmão tinha mudado e não agiria de forma preconceituosa em relação a sua orientação sexual e expressão de gênero.

Ela, então, pegou um ônibus do Rio de Janeiro para Dourados e se instalou na casa onde vive o irmão, a mulher e os filhos do casal, duas meninas de 16 e 13 anos, e um menino de 9. Desde que chegou, Alejandra passou a me comunicar que o clima na casa estava crescentemente hostil, com muitas brigas, e que mesmo sem ser o alvo das brigas muitas vezes ela era envolvida. Relatou que a mulher do irmão passou a se incomodar com sua presença na casa, mesmo sabendo das recomendações de isolamento por conta da pandemia de Covid-19. A mulher do irmão parecia estar preocupada com a relação de Alejandra e seus filhos, principalmente as meninas, insinuando que temia que Alejandra abusasse sexualmente delas por ser lésbica. Alejandra me disse que passou a ficar trancada no quarto até a hora de todos irem dormir e só aí podia sair para sala da casa, ou para a cozinha. Às vezes ia até a casa de um amigo gay e vizinho para cozinhar e dormir.

A pandemia atrapalhou os planos de Alejandra de conseguir uma entrevista de emprego na empresa em que trabalha o irmão. Em abril de 2020 ela disse que queria retornar ao Rio de Janeiro, pois só aqui sentia-se parte de uma família, porém estava insegura, sem saber se haveria ônibus realizando o trajeto depois de receber notícias que a rodoviária da cidade estava fechada. No dia 14 de abril contou-me que também cogitava voltar para a Venezuela, pois temia pela saúde das filhas e acreditava que a situação do país iria piorar muito com o retorno de venezuelanos para lá. Dois dias após ela ter me contado esse desejo de retorno, me manda uma mensagem dizendo que havia tentado suicídio após uma briga com a mulher do irmão, sendo expulsa em seguida por ele. Na mensagem ela também se referia à impossibilidade de retorno à Venezuela para estar com suas filhas, pois, segundo ela, "é impossível viver como lésbica lá". A partir de então ficou na casa de uma amiga e esperou a saída da primeira parcela do auxílio emergencial fornecido pelo governo federal para conseguir comprar uma passagem de ônibus para o Rio de Janeiro.

No dia 3 de junho acordei por volta das 8h e havia uma mensagem no meu celular de um número desconhecido dizendo: "Bom dia, a Alejandra foi roubada e não tem como ir embora, ela está na Rodoviária Novo Rio e pediu pra você ajudá-la". A mensagem foi enviada às $6 \mathrm{~h} 30 \mathrm{~m}$. Mandei mensagem para o número perguntando se a pessoa ainda estava com ela e recebi uma resposta dizendo que tinha dado alguma quantia em dinheiro pra Alejandra conseguir chegar na casa de amigos. Às 9h Alejandra me ligou de outro celular desconhecido e disse que tinha ido para a casa de sua amiga em Nova Iguaçu, mas a amiga estava com sintomas de Covid-19 e ela não queria ficar ali pois estava, segundo suas palavras, "com terror de pegar o vírus." Ela me narrou posteriormente suas impressões: 
Eu tenho medo de morrer, é verdade, por minhas filhas, minhas três filhas. Se eu faltar um dia, o que vai ser das minhas filhas? Eu sei que não estou perto delas e dói, dói, porque, cara... é muito preconceito. Eu fui afastada das minhas filhas pelo que sou hoje, mas eu não tenho vergonha do que sou hoje... mas foi a causa desse afastamento da minha família, das minhas filhas, de tudo... porque a gente é rejeitada da sociedade. Aí quando minha amiga falou que estava com Covid, eu não fiquei com medo não, eu fiquei com terror de pegar o vírus. Eu não sabia que ela estava com isso, porque não tinha internet, nem celular. Aí quando cheguei lá na casa dela, a gente se falou afastada, ela lá no canto e eu aqui, a gente quase que gritava, foi quando liguei pra vocês. Tinha que sair dali. (Transcrição de áudio via aplicativo Whatsapp, junho 2020)

Como sua amiga estava com sintomas da doença causada pela Covid-19, Alejandra ficou sem ter para onde ir em meio ao período de isolamento social provocado pela pandemia. Na LGBT+Movimento, já havíamos comentado com Alejandra sobre a Casa Nem, casa de acolhimento para pessoas LGBTI+ em situação de vulnerabilidade, quando esteve na eminência da situação de rua. Alejandra nos pediu ajuda para chegar até a sede da Casa Nem que, na ocasião, estava localizada no bairro de Copacabana, bastante distante do município de Nova Iguaçu onde se encontrava.

Esta é uma situação bastante comum no dia a dia da LGBT+Movimento: a dificuldade de locomoção pela cidade devido ao preço elevado das passagens. Alejandra não possuía o valor total das passagens necessárias para chegar até a Casa Nem. Ela também não possuía conta bancária, outra dificuldade muito reportada pelos solicitantes de refúgio atendidos pela organização. O difícil reconhecimento do Protocolo de Solicitação de Refúgio, como documento de identificação oficial de solicitantes de refúgio no território brasileiro, tem representado uma barreira de acesso na hora de abrir uma conta bancária. A solução para garantir a mobilidade na cidade vem muitas vezes da ajuda de amigos ou vizinhos que emprestam dinheiro ou suas próprias contas bancárias para transferência por terceiros, mas com certa frequência essa opção também não é possível. Como foi o caso de Alejandra. Felizmente Alejandra lembrou que no meio de suas coisas tinha guardado o cartão RioCard de passagem e consegui efetuar uma recarga com cartão de crédito. Alejandra deixou a casa da amiga e foi rumo à Casa Nem, onde ficou 15 dias em isolamento antes de poder circular nas áreas comuns da casa. No dia 12 de junho a LGBT+Movimento recebeu uma doação de um aparelho de celular usado, que entregamos para Alejandra assim que ela deixou o isolamento da casa e pode, por fim, comunicar-se com as filhas novamente.

\section{“De qual pandemia estamos falando?"}

A trajetória de Alejandra, que se inicia bem antes da pandemia, mas que também é cruzada por ela, nos permite pensar o impacto da pandemia da Covid-19 na vida de migrantes e refugiados e a importância do debate interseccional no campo de mobilidades, gênero e sexualidade. As interseccionalidades são 
frequentemente reduzidas ou apagadas pelo predomínio das considerações jurídicas e burocráticas que narram histórias de migrantes e refugiados, a partir de seus processos de elegibilidade legal e não de suas próprias narrativas (Antonucci, 2020). Há na trajetória de Alejandra vulnerabilidades que dizem respeito ao ser lésbica, como a situação de preconceito narrada por ela na casa de acolhimento para mulheres migrantes e refugiadas e na casa de seu irmão. Outras vulnerabilidades parecem estar ligadas, de forma mais específica, ao ser mulher, como as tentativas de estupro que ela sofreu no deslocamento da Venezuelana para o Brasil. Há ainda vulnerabilidades que estão mais explicitamente associadas ao seu estatuto migratório como solicitante de refúgio, por exemplo: a problemática em torno do difícil acesso a políticas públicas. De maneira geral, as dificuldades e possibilidades cotidianas vivenciadas por Alejandra partem de um conjunto de diferenças de gênero, classe, sexualidade e estatuto migratório que se interseccionam e expõem uma série de expectativas e lugares sociais (Crenshaw, 1992), bem como situações de violência, sofrimento e agência. Os refugiados, enquanto condição jurídica, têm sido compreendidos de uma forma um tanto genérica quando no isolamento de outros marcadores sociais da diferença, sendo muitas vezes admitidos como uma massa de sujeitos heterossexuais, cisgêneros, em sua maioria do gênero masculino (Teixeira, 2015). Ao discutir o silenciamento dos campos acadêmicos em relação à experiência de vida de migrantes lésbicas, Luibhéid (2019) ressalta a importância do que me referi nesse artigo como "a terceira dimensão do contar":

Crenshaw is describing intersectionality, meant not in the neoliberal sense of "adding" together considerations of race, gender, class, sexuality, and citizenship status to derive understanding of someone's identity conceived as personal property, but in the sense of being located at the intersections of several nondominant positionalities, which results in "the lack of available and widely comprehended narratives to communicate the reality of [one's] experience to the world. $(2019$, p. 2)

A predominância da concepção burocrática e jurídica, que ainda domina as análises ligadas ao refúgio, está profundamente associada à ausência de narrativas como a de Alejandra e a pouca compreeensão da vida de migrantes e refugiados através da perspectiva interseccional de análise. As diferentes posicionalidades interligadas no caso de Alejandra lembram um trecho da reflexão de Ueslei Solaterrar, durante o evento das Jornadas CLAM (Centro Latino-Americano em Sexualidade e Direitos Humanos), em junho de 2020. Em um encontro que abordava a pandemia do Covid-19 e a violência nas favelas e periferias, Ueslei refletiu sobre suas experiências como coordenador do CAPS (Centro de Atenção Psicossocial) Casa Verde localizado na Baixada Fluminense, no Rio de Janeiro. Ueslei afirmou que não estamos vivendo a mesma pandemia pois não disponibilizamos dos mesmos recursos para atravessá-la e em seguida perguntou: de qual pandemia estamos falando?

A trajetória de Alejandra demarca o que Ueslei quis dizer com sua interrogação, ou seja, estamos atravessando múltiplas pandemias e uma coisa 
é certa: as dificuldades não são as mesmas. As desigualdades operacionalizam o trânsito heterogêneo dos impactos desiguais, que diferenciam radicalmente as experiências sociais desse mesmo evento, a ponto de, como sugere Ueslei, necessitarmos saber de qual pandemia falamos antes de falarmos sobre ela.

Nesse contexto, muito tem-se debatido sobre a questão do isolamento social, sobretudo da adoção de um regime tipo lockdown ou não. Mas, como pensar essas intervenções de "tamanho único" (Ortega, Behague, 2020) quando a noção de casa tanto para pessoas que se identificam como LGBTI+ quanto para pessoas migrantes e refugiadas frequentemente não é o lugar onde se está, ou onde se mora? A impossibilidade de estar restrito em casa ou em algum lugar produz uma série de outras dinâmicas de mobilidades. No caso de Alejandra, de um lado ela exprimiu o desejo, mas também a impossibilidade, de retornar à Venezuela por não poder viver plenamente sua sexualidade e, ao mesmo tempo, via crescer os conflitos com a esposa do irmão, tornando sua permanência na casa também impossível. Sem zonas intermediárias que permitissem a sua "imobilidade", Alejandra retorna ao Rio de Janeiro novamente. Do ponto de vista do evento da pandemia do Covid-19 a mobilidade de Alejandra parece um risco, sendo o Rio de Janeiro um dos epicentros da pandemia no Brasil. E do ponto de vista da violência de gênero sofrida na casa do irmão parece ser esta uma espécie de "mobilidade forçada". Porém, talvez seja possível significar sua mobilidade de outra maneira: ela parece mover-se de um projeto e/ou uma forma de agência ${ }^{11}$ direcionada à morte - em relação à sua tentativa de suicídio após os episódios violentos na casa do irmão - para um projeto ou uma forma de agência voltados para a vida/sobrevivência - o medo do coronavírus e esse agir para sobreviver com desejo de reencontrar as filhas.

A homogeneização presente nas intervenções de "tamanho único", comentadas por Ortega e Behague, e a categorização a priori dos retornos de venezuelanos como "voluntários" por parte das autoridades colombianas, evidencia que não levar em consideração a dimensão complexa e variável dos contextos e interseccionalidades implicadas em trajetórias como as de Alejandra apaga o âmbito biográfico do evento da pandemia do Covid-19, dando centralidade a ideia de que essa é uma crise sanitária e não da vida em si mesma, como defende Horton (2020).

\section{Considerações Finais}

O tema das mobilidades está no centro das reflexões sobre a pandemia da Covid-19. Um dos objetivos desse artigo foi apresentar a estreita relação entre os regimes de mobilidade/imobilidade e as desigualdades sociais abismais, sem deixar de apresentar as (re)configurações das mobilidades durante o contexto da

\footnotetext{
11 Utilizo a noção de agência como "não como um sinônimo de resistência em relações de dominação, mas sim como uma capacidade para a ação criada e propiciada por relações concretas de subordinação historicamente configuradas" (Mahmood, 2019, p. 123).
} 
pandemia, a partir da trajetória de uma mulher lésbica venezuelana e solicitante de refúgio. Apesar de estarmos falando de um evento pandêmico global, a pandemia é singularizada e atualizada a cada "contar", por isso múltiplas são as pandemias e múltiplos são os trânsitos.

A mobilidade e a vida de pessoas migrantes e refugiadas foram impactadas e (re)configuradas no contexto pandêmico, porém tais deslocamentos não são novos elementos entre esta população. Eles fazem parte de um vasto conjunto de diferenças e desigualdades que condensam-se e potencializam-se em corpos marcados social e historicamente por elas.

Busquei, a partir da trajetória de Alejandra, problematizar os diferentes e desiguais sentidos e efeitos da construção de uma orientação sanitária de "tamanho único", que tem guiado a compreensão e a gestão das mobilidades em tempos de pandemia, sem levar em conta as circunstâncias sociais desiguais de migrantes e refugiados ao Sul Global. Como refletem Blanc, Laugier e Molinier (2020) sobre as exacerbadas desigualdades de gênero em tempos pandêmicos, "pensar na crise não é pensar o depois" e sim "na longa lista de desigualdades" que estão ainda mais em evidência nesses tempos.

\section{Referências bibliográficas}

AGUIÃO, Silvia. Fazer-se no "Estado": uma etnografia sobre o processo de constituição dos "LGBT" como sujeitos de direitos no Brasil contemporâneo. Campinas: UNICAMP, 2014.

ANTONUCCl, Nathália. Entrecruzamento entre migração, gênero e sexualidade: experiências de vida de mulheres não-cisheterossexuais venezuelanas e solicitantes de refúgio. Rio de Janeiro: Universidade Federal Fluminense, 2020.

BLANC, Nathalie; LAUGIER, Sandra; MOLINIER, Pascale. O preço do invisível: As mulheres na pandemia. DILEMAS: Revista de Estudos de Conflito e Controle Social, Reflexões na Pandemia, p. 1-13, 2020.

CARRARA, Sérgio. As ciências sociais entre múltiplas epidemias. Physis, v. 30, n. 2, p. 1-6, 2020.

CRENSHAW, Kimberle. Whose Story is it Anyway? Feminist and Antiracist Appropriations of Anita Hill. In: Race-ing justice, en-gendering power: essays on Anita Hill, Clarence Thomas, and the construction of social reality. New York: Pantheon Books, 1992.

DAS, Veena. Vida e Palavras: A Violência e sua Descida ao Ordinário. São Paulo: Unifesp, 2020.

DAS, Veena. Affliction: Health, Disease, Poverty. New York: Fordham University Press, 2015.

DAS, Veena; POOLE, Deborah. Anthropology in the Margins of the State. New Mexico: School of American Research Press, 2004.

DOUGLAS, Mary. Purity and Danger: An Analysis of Concepts of Pollution and Taboo. London: Routledge, 1966. 
FACUNDO, Angela. Colombianos refúgiados no Sul e Sudeste do Brasil. Rio de Janeiro: Universidade Federal do Rio de Janeiro, 2014.

FASSIN, Didier. Humanitarian Reason: A Moral History of the Present. Los Angeles: University of California Press, 2012.

FRANÇA, Isadora Lins; FONTGALAND, Arthur. Gênero, sexualidades e deslocamentos: notas etnográficas sobre imigrantes e "refugiados LGBTI" no Norte do Brasil. REMHU, Revista Interdisciplinar da Mobilidade Humana, Brasília, v. 28, n. 59, p. 49-68, 2020.

FREIRE, Lucas. Subnotificação e negacionismo: o que conta como real em uma (in)visível pandemia. Boletim Cientistas Sociais, n. 34, 2020. Disponível em: < http://anpocs. org/index.php/publicacoes-sp-2056165036/boletim-cientistas-sociais/2348boletim-n-34-cientistas-sociais-e-o-coronavirus > . Acesso em: 09.01.2021.

HORTON, Richard. Offline: A global health crisis? No, something far worse. The Lancet, v. 395, n. 10234, p. 1410, 2020. Disponível em: <http://dx.doi.org/10.1016/ S0140-6736(20)31017-5>.

LATOUR, Bruno. La crise sanitaire incite à se préparer à la mutation climatique. Le Monde, 15.03.2020. Disponível em: <https://www.lemonde.fr/idees/article/2020/03/25/ la-crise-sanitaire-incite-a-se-preparer-a-la-mutation-climatique_6034312_3232. html>. Acesso em: 09.01.2021.

LUIBHÉID, Eithne. Migrant and refugee lesbians: Lives that resist the telling. Journal of Lesbian Studies, v. 24, n. 2, p. 57-76, 2019. DOI: 10.1080/10894160.2019. 1622935. Disponível em: <https://www.tandfonline.com/doi/abs/10.1080/108941 60.2019.1622935>. Acesso em: 20.09.2020.

MAHMOOD, Saba. Teoria feminista, agência e sujeito liberatório: algumas reflexões sobre o revivalismo islâmico no Egito. Etnografica, v. 23, n. 1, p. 135-175, 2019. DOI: 10.4000/etnografica.6431.

ORTEGA, Francisco; BEHAGUE, Dominque P. O que a medicina social latino-americana pode contribuir para os debates globais sobre as políticas da covid-19: Lições do Brasil. Physis, v. 30, n. 2, p. 1-13, 2020. DOI: 10.1590/S0103-73312020300205.

PRATES, Lubi. Um Corpo Negro. São Paulo: Nosotros Editoral, 2019.

PRECIADO, Paul. Aprendiendo del virus. El País, 28.03.2020. Disponível em: < https:// elpais.com/elpais/2020/03/27/opinion/1585316952_026489.html>. Acesso em: 09.01.2021.

RUSEISHVILI, Svetlana. Quatro lições da pandemia sobre a mobilidade no mundo contemporâneo. UFSCAR, 2020. Disponível em: <http://www.ppgs.ufscar.br/ sociologia-na-pandemia-5/>. Acesso em: 10.01.2021.

TEIXEIRA, Marcelo. "Metronormatividades" nativas: migrações homossexuais e espaços urbanos no Brasil. Áskesis. Revista des discentes do Programa de Pós-Graduação em Sociologia da UFSCar, v. 4, n. 1, p. 23-38, 2015.

UNHCR. Convenção Relativa ao Estatuto dos Refugiados. 1951. Disponível em: <https://www.acnur.org/fileadmin/Documentos/portugues/BDL/Convencao_ relativa_ao_Estatuto_dos_Refugiados.pdf $>$. Acesso em: 26.11.2020. 